\title{
Gallstone impaction at the orifice of the duct of Wirsung successfully treated via needle-knife papillotomy
}

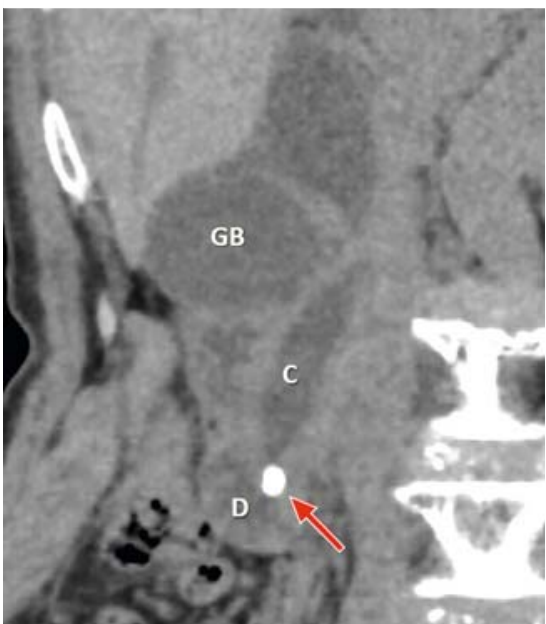

- Fig. 1 Reconstructed coronal image of a computed tomography scan of the abdomen showing a gallstone, approximately $8 \mathrm{~mm}$ in size, impacted at the ampulla of Vater (arrow) and mild common bile duct dilation. GB, gallbladder; C, common bile duct; $D$, second part of the duodenum.

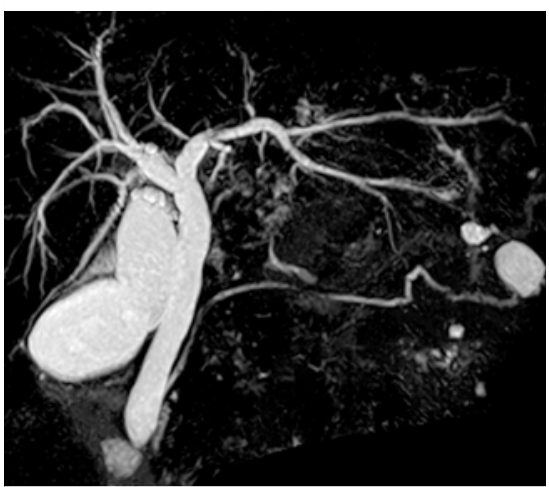

- Fig. 2 Magnetic resonance cholangiopancreatography showing mild common bile duct dilatation but no dilatation of the pancreatic duct and no evidence of gallstone impaction at the ampulla of Vater.

An 80-year-old woman presented with epigastralgia. Laboratory investigations demonstrated markedly elevated cholestatic parameters and slightly elevated pancreatic enzymes, including total bilirubin $3.6 \mathrm{mg} / \mathrm{dL}$ (normal range $0.4-$ $1.5 \mathrm{mg} / \mathrm{dL}$ ), aspartate aminotransferase
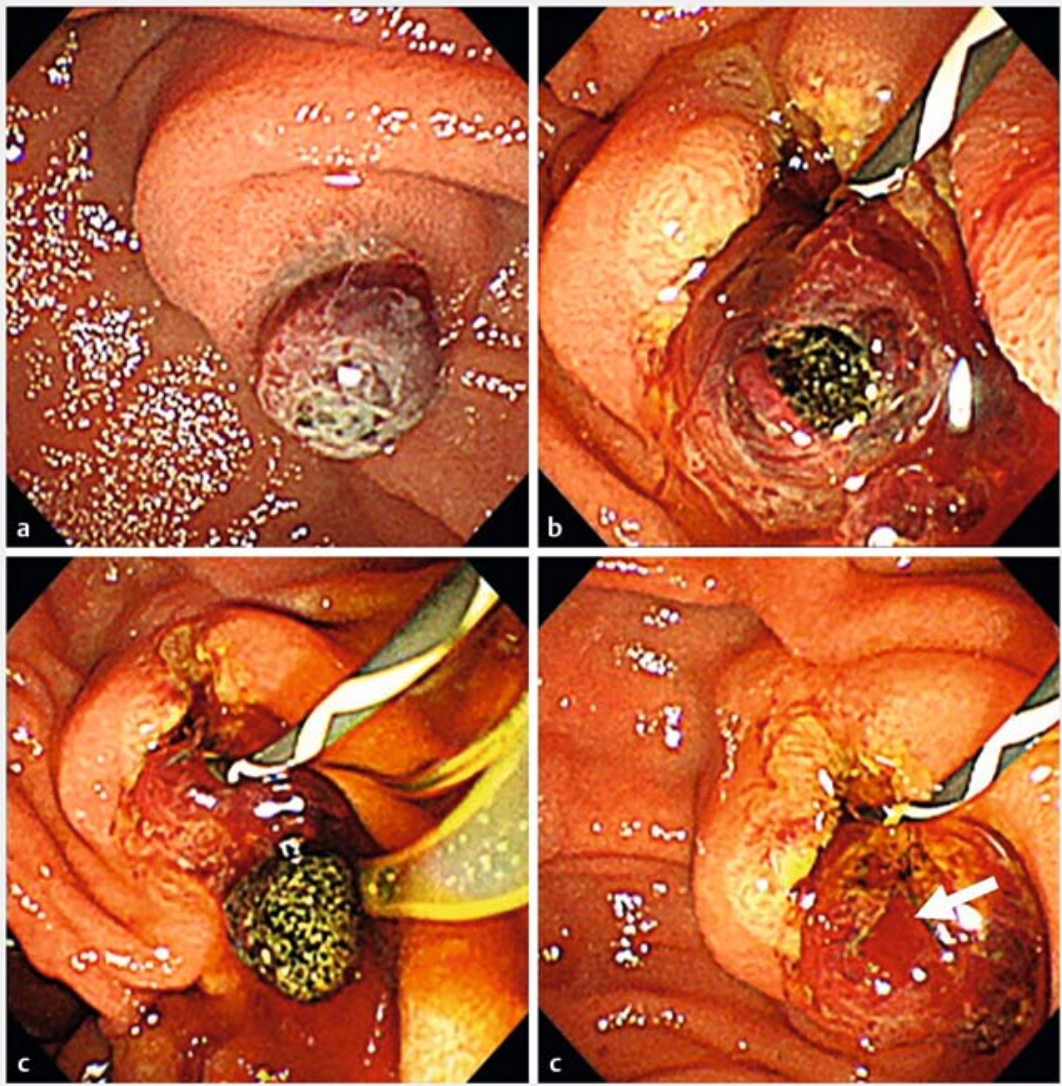

Fig. 3 Endoscopic views showing: a a gallstone impacted at the orifice of the ampulla of Vater, which was reddish and protruded; $\mathbf{b}$ after guidewire insertion into the common bile duct and endoscopic sphincterotomy, gallstone impaction at the orifice of the duct of Wirsung; $\mathbf{c}$ the gallstone being removed immediately after needle-knife papillotomy; $\mathbf{d}$ the point of impaction (arrow).

$725 \mathrm{U} / \mathrm{L}(13-30 \mathrm{U} / \mathrm{L})$, alanine aminotransferase $637 \mathrm{U} / \mathrm{L}(10-42 \mathrm{U} / \mathrm{L})$, alkaline phosphatase $353 \mathrm{U} / \mathrm{L}(38-113 \mathrm{U} / \mathrm{L})$, Y-glutamyl transpeptidase $486 \mathrm{U} / \mathrm{L}(9-$ $32 \mathrm{U} / \mathrm{L})$, amylase $144 \mathrm{U} / \mathrm{L}(44-132 \mathrm{U} / \mathrm{L})$, pancreatic amylase $47.2 \% \quad(13.0-$ $47.0 \%)$, and lipase $70 \mathrm{U} / \mathrm{L}(11-59 \mathrm{U} / \mathrm{L})$. Her white blood cell count and C-reactive protein level were within normal limits. Abdominal computed tomography $(\mathrm{CT})$ revealed a gallstone (approximately $8 \mathrm{~mm}$ in size) impacted at the ampulla of Vater ( $\triangleright$ Fig. 1), but the gallstone was not shown on magnetic resonance cholangiopancreatography (MRCP). Additionally, CT and MRCP showed mild common bile duct (CBD) dilatation and cholecystolithiasis, with no evidence of pancreatitis or dilatation of the pancreatic duct ( $\triangleright$ Fig. 2).

Endoscopic retrograde cholangiopancreatography $(\mathrm{ERCP})$ revealed gallstone impaction at the orifice of the ampulla of Vater, which was reddish and protruded ( $\triangleright$ Fig.3a). Cannulation via the orifice of the impacted gallstone compressed the duct of Wirsung unexpectedly. Subsequently, endoscopic retrograde cholan- 


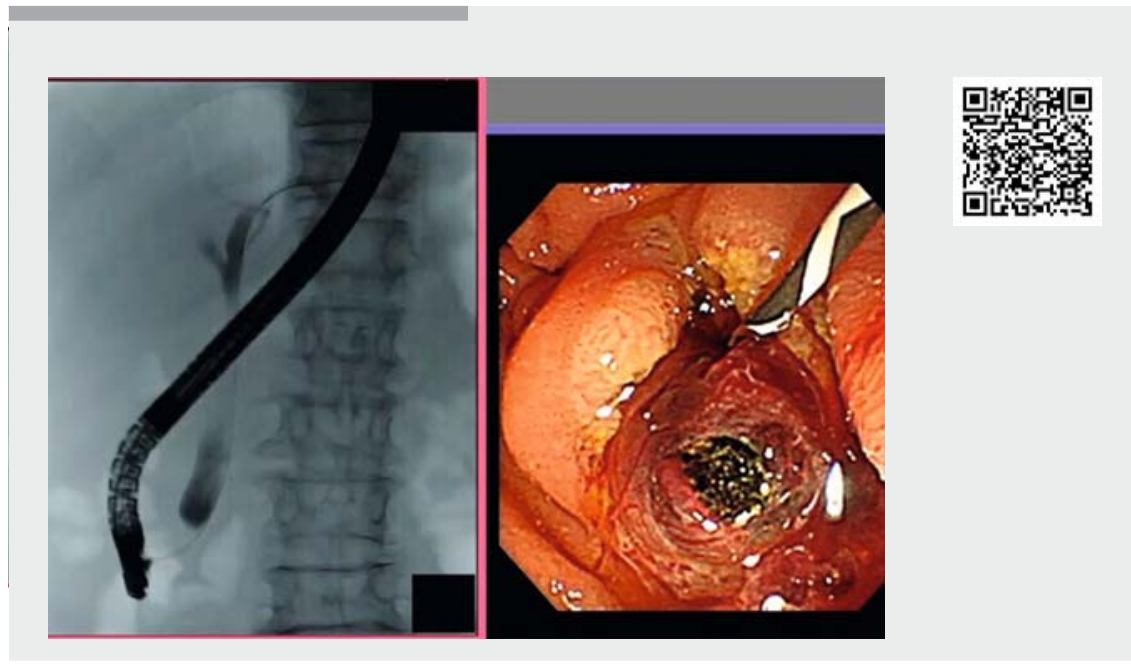

Video 1 Endoscopic extraction of a gallstone impacted at the orifice of the duct of Wirsung using endoscopic sphincterotomy and needle-knife papillotomy.

giography (ERC) was successfully performed via cannulation slightly to the oral side of the orifice of the impacted gallstone. Both ERC and intraductal ultrasonography revealed no CBD stones. After endoscopic sphincterotomy, we confirmed that the gallstone was impacted at the orifice of the duct of Wirsung ( $\vee$ Fig.3b). Needle-knife papillotomy was additionally performed and the gallstone was removed uneventfully ( $>$ Fig. 3 c,d). Finally, endoscopic biliary and pancreatic stents were inserted into the CBD and the duct of Wirsung for drainage ( $\vee$ Video 1 ).

The patient's postoperative course was good and the two stents were removed on postoperative day 1 . She was discharged 7 days postoperatively.

Gallstone impaction at the orifice of the duct of Wirsung is extremely rare. Needle-knife papillotomy may be an effecflict of interest.
Corresponding author

Takashi Abe, MD, PhD

Department of Gastroenterology, Oita Kouseiren Tsurumi Hospital, Tsurumi 4333, Beppu City, Oita 874-8585, Japan

Fax: +81-977-237884

takashi0315@oita-u.ac.jp

\section{Bibliography}

Endoscopy 2021; 53: 982-983

DOI 10.1055/a-1290-6691

ISSN 0013-726X

published online 11.11.2020

(c) 2020. Thieme. All rights reserved.

Georg Thieme Verlag KG, Rüdigerstraße 14,

70469 Stuttgart, Germany

\section{ENDOSCOPY E-VIDEOS}

https://eref.thieme.de/e-videos gallstone impaction at this site.

Endoscopy_UCTN_Code_CCL_1AZ_2AD

\section{Competing interests}

The authors declare that they have no con-

\section{The authors}

Takashi Abe ${ }^{1}$, Takayuki Nagai ${ }^{1}$, Takehiko Nariyasu' ${ }^{1}$, Marina Hamamoto ${ }^{1}$, Masato Hanzawa', Yasuhisa Hiroshima ${ }^{1}$, Kazunari Murakami ${ }^{2}$

1 Department of Gastroenterology, Oita Kouseiren Tsurumi Hospital, Beppu, Japan

2 Department of Gastroenterology, Faculty of Medicine, Oita University, Yufu, Japan 